\title{
Research on Dissemination and Translation of Contemporary Literature in Shaanxi Native Culture
}

\author{
Jiaying $\mathrm{Ma}^{1}$ \\ ${ }^{1}$ Xi'an Fanyi University, Xi'an, Shaanxi, 710077 \\ 59624917@163.com
}

Keywords: Shaanxi Modern Literature; Dissemination of Local Culture; Local Culture Translation

\begin{abstract}
In today's globalized environment, our national culture began to go abroad. In contemporary writers in Shaanxi, Lu Yao, Jia Pingwa have begun to move international and translated into other languages and spread abroad. However, the differences between national cultures make a lot of problems in the process of dissemination and translation, which limits the spread of Shaanxi local culture. This paper studies Shaanxi contemporary literature dissemination and translation of local culture, aims to enhance contemporary literary works Shaanxi local cultural dissemination of constructive comments.
\end{abstract}

\section{Introduction}

History of cultural exchange between China, many cases have proven mutually beneficial cultural exchange is a thing, even though such exchanges and is entirely based on an equal relationship, but it also confirmed to the value of local culture and ignore nationality other diverse cultures worldwide, or blindly importance and integration of global culture while ignoring local culture spread, do not make marginalized and disadvantaged obtain long-term vitality of local culture [1]. In Shaanxi Modern literature, although the author depicted in the works, the show is a different personality and story work, but are invariably of the Shaanxi local culture into one. In external communication and translation process, due to differences in national cultures, translation or communicators are not well local culture works in perfect reproduction, which is today the national character of the local culture in the dissemination and translation of the main problem.

\section{Development and Characteristics of Shaanxi local Literature}

Shaanxi native literature can be summarized in three phases: the first phase, from 1950 to 1960; the second stage, in the late 1960s - the late 1970s; the third stage of the late 1970s-mid-1990s [2]. In the first stage, Shaanxi Local Literature in the initial stage of development, suddenly fell into the second phase of the trough, and subsequently rose again in the third stage. Through these three stages of research, we can find that Shaanxi native literature to some extent constrained by the country's development. Before the Cultural Revolution period and after the Cultural Revolution, Shaanxi local have emerged a number of excellent literary works. Especially after the Cultural Revolution, which is the third stage, the growing prosperity of Shaanxi native literature, and even the literary works of a number of international influence. These works created broader themes, literary themes and structure more reasonable, creative approach gradually enriched. But after the mid-1990s, the development of Shaanxi literature gradually slowed.

Shaanxi Modern literary works have a strong local culture, one of its original intent because of its deeply influenced by "Yan'an culture". Yan'an in Shaanxi Cultural Centre rise native literature plays a decisive role, Shaanxi native literature significance can not be ignored [3]. Throughout the development process throughout Shaanxi native literature, you will find deep impact Shaanxi Local Literature is two things: First, Mao Zedong in Yan'an ten years, the second is Beijing educated youth to jump the queue. Both periods have a lot of highly qualified intellectuals moved to Shaanxi, Shaanxi local literature played a good role in promoting development. Such as the famous writer Liu Qing, he created a spirit of Shaanxi literature and it is the spiritual pillar of Shaanxi generations 
of writers. Shaanxi writers imitate, so that Shaanxi literature have similar literary tastes, writing style, writing style, formed a literary style with a Shaanxi native culture.

\section{Problems in Shaanxi Local Cultural Dissemination of Contemporary Literature and Translation}

Native and Non-Native Contradiction Propagation. Shaanxi Modern literature spread mainly through official propaganda, or translate spread by others. The former is the government body, it is more important is for everyone through the dissemination of these works show Shaanxi local culture, creating a line with the mainstream values of the image. But the spread of the works to be translated by other people, is largely self-screening by the Evangelist, it was communicators to meet their own needs and carried out. In the screening process, the communicator will likely Shaanxi native culture with a strong work from culling, to show you a different literary works. As Lu Yao's "Ordinary World," the authors of live performance imagined in rural Shaanxi and reading to change the fate of this view, but some other versions see is the image of a backward rural Shaanxi, as well as people to become way "top man" and means used.

Contemporary literature should reflect a nation or region in the most authentic culture and contemporary forms, but for various reasons, communicators will need to work according to their own native culture in carefully selected. Such work is already in some ways it can not be called "original" because it should have with their own native culture and communication has been greatly reduced.

Contradictions Build Self-Image with Others on Image Interpretation. Shakespeare once said, there are a thousand people in the eyes of Hamlet. This shows that in the same work, even the same character, the author wants to convey to the reader, and the reader's own experience is different. It depends on the reader more of their own cultural back-ground, and the work of interpretation, of course, the author's own creative ability and character construction practices. If there is no good communicators understand want to express the author's intention, then the dissemination process will be deviations, meaning that eventually led to the spread of original works and want to express very different. In the "White Deer", the writer Chen Zhongshi wants to show that, in the country's turbulent, Shaanxi farmers in this environment of fate and life. In the outside and the inside is not safe, it is stubborn guardian of ancestral reputation, or choose to go into exile to break a world. There are a lot of text description of Shaanxi rural scenery, from the beginning of the whole work begins to lay desolate tone. But some of communicators will be criticized as a mere feudal thinking behind the works, to work in the construction of the characters and the story is just be superficial, thin depiction of which implied a deep local culture has also been greatly weaken. So naturally there is no way to revealing the work should be good, they naturally can not convey the intent of the author wanted to convey.

Communication and Extraterritorial Contradictory Local Translation. Translated into the language of the national audience for the subtle habits, hobbies and grasp the unique character subtle aspects of aesthetic taste on extraterritorial translation shows local translation elusive advantage [4]. Translation of the merits makes a work, a direct impact on the spread of the work outside. Especially for regional Shaanxi has obvious contemporary literature, his works implied deep local culture for local readers, it is self-evident. With the author because they have similar growth environment and cultural background, I can well understand the meaning expressed by the author wants to experience the style and creative expression of the author constructed beauty. But the reader is not extraterritorial such conditions. Extraterritorial translation process, the translator will translate into a combined area of reading preferences for translation, so that works can be translated into better readers of the region. Even so, but based on different cultures, expression and depict the same words in the translation error still occurs, so that works much influenced by the local culture.

Translation Practice and an acceptance of the time difference, the language difference are closely related to [5]. The so-called time difference is the degree of time in another region an area of cultural acceptance. If China accepts foreign literature of the time for nearly a century, our readers 
have adapted to the writing style and text style of foreign literature, but foreign contact time for our national character of literature is only a short two or three decades, the extraterritorial Translation is also in its infancy stage. Under such conditions, the difficulty of nationality literature dissemination and translation of natural increase. The language difference is the difference between [6] to master different languages to understand other people's language literary works produced. Even in mainland China, the region also has its own unique dialect and regional cultures, so they will increase the difficulty of Shaanxi Literature Native cultural transmission and translation.

\section{Shaanxi Modern Literary Works Effectively Enhance Local Culture Dissemination and Translation Strategies}

Importance of Local Content and Carrier of Cultural Transmission. Shaanxi Literature is important to disseminate the contents of the local culture with the carrier. Shaanxi local culture, Shaanxi contemporary literature, "root", almost all of Shaanxi Modern literature, have spent a lot of ink to depict the lives of farmers in Shaanxi, which is actually the local culture of Shaanxi direct description. People's habits, customs, are interspersed in another story. So in the propagation of Shaanxi local culture, pay attention to contemporary literary works reproduced Shaanxi local culture, as much as possible to retain Shaanxi Modern literary works of local culture, "authentic." Following this dissemination and translation, in order to maximize the retention works in the local culture. As communicators understanding of local culture and acceptance of Shaanxi, in the dissemination and translation of "loss" of the local culture will also be gradually reduced.

Identify the Target Audience and Make the Appropriate Text Selection. Known as China Modern Literature chief translator, Mr. Ge Hao has said that translation should identify the target audience to understand the target audience's reading habits and preferences, and thus targeted translation. For example, US readers like political fiction and detective type more, to describe the characters' inner work more but interest is not high. Therefore, in the process of translation, the translator to combine the reader's reading habits and preferences will work in the local culture organic integration, so that readers can have a different reading experience.

Translation Using a Variety of Methods to Achieve Maximum Reproduction of Works of Local Culture. Translation methods are literal, paraphrase translation and rotation in three ways: through the literal translation of the text directly, but does not support a translator attached to every phrase, and should value the words of the overall structure and beauty, so that it to better show the works of the local culture. Translation method is a changeable words, a more appropriate translation with another word or way to achieve the reproduction of the original "meaning." Chinese ancients pay attention to "Tibetan mountain temple" mood beauty and natural beauty, which also affected the writing style of Shaanxi literature. In the translation, the use of a literal rule will completely destroy the original words in the United States, let alone retain their rightful indigenous culture of. Conversion of translation is a phrase or a word in the speech translation bits, so that the closer to the original meaning of the sentence, but also in line with the target area readers aesthetic and habits. Especially for literary works idiom, using turn translation, not only embodies the right of the original meaning of idioms, also inherited the original idiom proper beauty.

\section{Conclusion}

In the process of communication and translation, the Shaanxi contemporary literature in the local culture will always be screened for various reasons, were excluded, which for the original, for the author is extremely disrespectful behavior. While in the process of translation and dissemination of works, the more the translator (communicators) is related to the level, but the real cause of the loss of local cultural text is its attitude. Shaanxi local culture is the soul of Shaanxi literature and it is the basis of Shaanxi modern literature. Disrespect, not the maximum protection of works of the local culture, there will be no way to spread out the essence of the works. 


\section{References}

[1] Qiao Yan. On The Buddhist Translation and Dissemination of Works Abroad-on Shaanxi Literature "Going Out". The Status Quo and Problems. Fiction Reviews, 2014,01: 75-83.

[2] Huang Hui. From Local Cultural Perspective of Cultural Transmission Function Brief Translation. Education Guide (Late), 2015,05: 166-167.

[3] Sun Liyang. Research Global Elements Shaanxi Literature. Fiction Reviews, 2015,03: 56-61.

[4] Jiang Zhiqin. Contemporary Communications Fictitious Character Chinese Method of Literary Study Abroad and Problems. Qinghai Social Sciences, 2013,03: 146-150, 156.

[5] Xiong Xiuyu. Factors Influence Overseas Chinese Contemporary Literature Analysis. Literary Review, 2013,01: 131-138.

[6] Wang Yongqi. Foreign Influence Shaanxi Literature. Shaanxi Education (Higher Education Edition), 2012,12: 10-11. 